\title{
CDMA, al servicio de instituciones, investigadores, profesionales y aficionados
}

El Centro de Documentación Musical de Andalucia (en adelante CDMA) está ubicado a los pies de la colina de la Alhambra, separada de ésta por el río y dando acceso al Albayzín.

Fue creado en 1987 por la Consejería de Cultura de la Junta de Andalucia como instrumento de investigación de la música andaluza, y desde sus inicios sus objetivos han sido reunirla, protegerla y difundirla. Los fondos de música abarcan la producción musical de ámbito internacional y los materiales recuperados por el Centro.

Los trabajos de investigación, recuperación, conservación y difusión patrocinados por el Centro tienen como objetivo la música de Andalucía en cualquiera de sus aspectos: popular, tradicional, clásica, religiosa, contemporánea, para lo cual se han establecido convenios de colaboración con otras instituciones (Iglesia Católica, universidades, asociaciones y organismos culturales). Fruto de estos convenios son las diversas publicaciones que edita el CDMA cada año.

Actualmente el CDMA depende de la Dirección General del Libro y del Patrimonio Bibliográfico y Documental, y aspira a ser una herramienta útil y cualificada al servicio de instituciones, investigadores, profesionales y aficionados de la sociedad en general.

\section{Departamento de Archivo, Biblioteca y Medios Audiovisuales}

Los fondos de música abarcan parte de la producción musical universal y más concretamente y en mayor número la música de Andalucía de todos los tiempos en todas sus formas.

\section{TIPO MATERIAL}

TOTAL TITULOS

$\begin{array}{ll}\text { Monografias (títulos) } & 8.355 \\ \text { Publicaciones periódicas (suscripciones) } & 351 \\ \text { Música impresa (partituras) } & 16.649 \\ \text { Casetes (unidades) } & 2.462 \\ \text { Cilindros fonográficos (unidades) } & 509 \\ \text { Cintas magnetofónicas (cintas) } & 315 \\ \text { Dats (unidades) } & 1.302 \\ \text { Discos de cartón (unidades) } & 195 \\ \text { Discos compactos } & 6.891 \\ \text { Discos de pizarra } & 5.620 \\ \text { Discos de vinilo } & 6.830 \\ \text { Rollos de pianola } & 1.100 \\ \text { Videos (cintas) } & 835 \\ \text { Total de materiales } & 51.219\end{array}$

Colecciones de Archivos singulares:

- Archivo de Joaquín Turina (digitalizado).

- Archivo de Ángel Barrios, desde la correspondencia hasta el archivo de partituras y una interesante colección de fotografía estereoscópica.

- Archivo de Francisco Alondo, incluye las partituras de su etapa granadina, hasta 1911. Discos de pizarra y otras grabaciones.

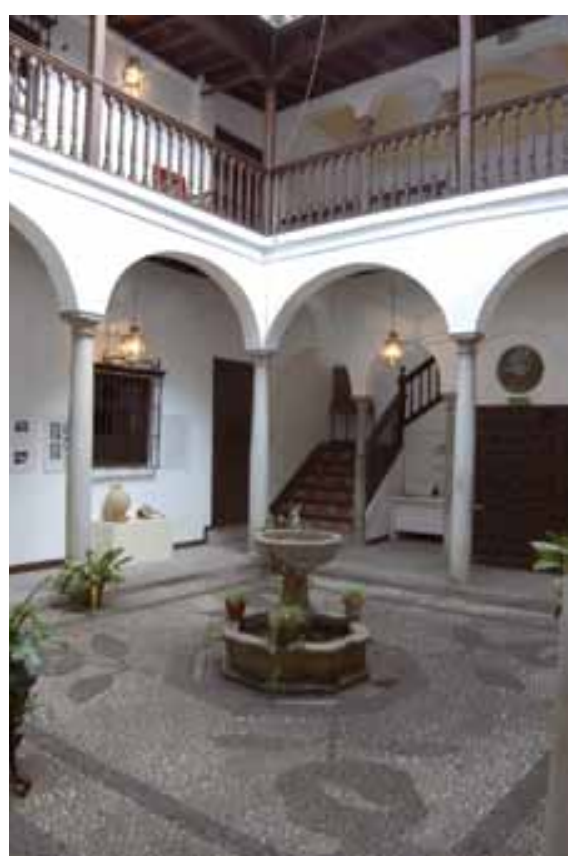

Patio interior del Centro de Documentación Musical de Andalucía. Fuente: CDMA

- Archivo sonoro de Juan de Loxa.

- Archivo de la Peña de la Platería, con grabaciones efectuadas desde 1960 hasta la fecha de hoy.

- Archivo Histórico Musical, colección en microfilm del fondo musical de los archivos de las catedrales de Andalucía.

- Archivo de Manuel Castillo, en depósito, originales de las partituras y digitalización.

- Archivo de partituras de la familia Palatín procedente del Teatro de la Maestranza de Sevilla.

- Colección de cilindros de cera procedente de la Facultad de Ciencias Económicas y Empresariales de la Universidad de Granada.

La Fonoteca se encarga de la conservación del material sonoro y visual perteneciente al fondo antiguo y moderno, su tratamiento y digitalización.

\section{Departamento de Documentación}

Las bases de datos gestionadas son:

- Entidades Musicales en Andalucia: incluye información sobre agrupaciones musicales y de danza, entidades dedicadas a documentación e investigación, concursos, cursos, festivales, ciclos, becas, congresos, asociaciones, instituciones públicas, entidades dedicadas a la enseñanza, comercios, salas de conciertos... El total de registros que contiene asciende a 9.010 .

Esta base de datos se ha ido actualizando basándonos en la selección de noticias de prensa y la información remitida al Departamento, así como por los propios usuarios que la forman.

- Compositores Andaluces Contemporáneos: permite conocer la vida y obra de los Compositores anda- luces contemporáneos más destacados del territorio andaluz. Además de permitir su visualización, incluye diversos servicios, como la impresión y descarga directamente desde nuestra página web (www.juntadeandalucia.es/cultura/centrodocumentacionmusical). Destacar la colaboración con la Asociación de Compositores Sinfónicos de Andalucia, y la creación del "Taller de mujeres compositoras", que se reúne anualmente en el Festival de música española de Cádiz.

\section{Unidad de Investigación, Conservación y} Exposiciones

La investigación se fomenta mediante las "Ayudas a proyectos de investigación musical", que la Dirección General del Libro y del Patrimonio Documental y Bibliográfico convoca periódicamente, y con convenios y acuerdos de colaboración con las Universidades de Andalucia y otras instituciones.

En esta unidad se planifica la conservación de los fondos del CDMA y su tratamiento, tanto general como de forma individualizada, así como del cuidado de las colecciones de instrumentos musicales, instrumentos mecánicos, fonográficos y soportes históricos.

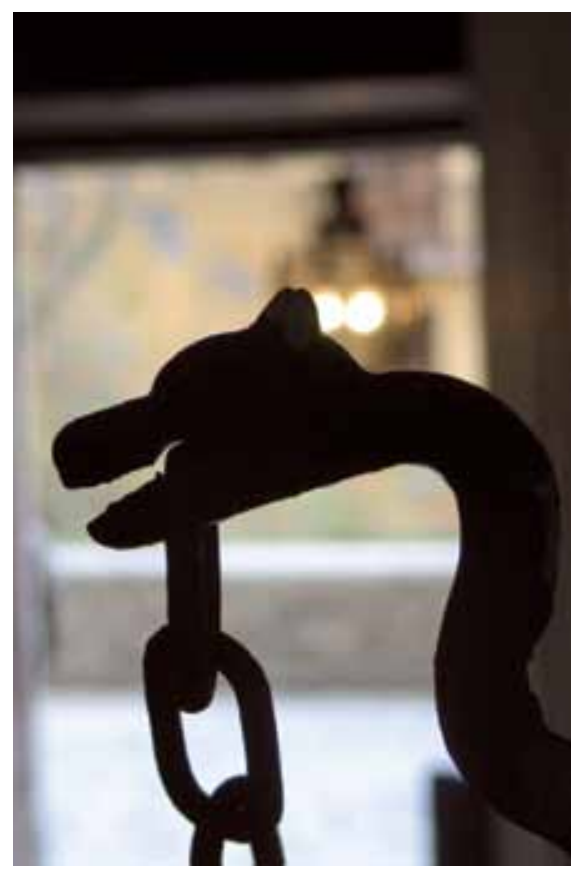

Detalle baranda del Centro de Documentación Musical de Andalucía. Fuente: CDMA

Se han puesto en marcha diversas exposiciones itinerantes por el territorio andaluz. Entre ellas destacar: Instrumentos Musicales de Barro en Andalucia; Paisajes Sonoros; Instrumentos Andalusies; Música mecánica, los inicios de la fonografía.

Reynaldo Fernández Manzano

Director del Centro de Documentación Musical de Andalucía 